\title{
Effective Use of the Potential of Rail Freight Corridors in the East - West Direction
}

\author{
Milan Dedík ${ }^{1 *}$, Matúš Dlugoš ${ }^{1}, J_{0 z e f}$ Gašparík $^{1}$ and Borna Abramović ${ }^{2}$ \\ ${ }^{1}$ University of Žilina, Department of Railway Transport, Univerzitná 8215/1, 01026 Žilina, Slovak \\ Republic; Email: matus.dlugos@fpedas.uniza.sk, milan.dedik@fpedas.uniza.sk, \\ jozef.gasparik@fpedas.uniza.sk \\ ${ }^{2}$ University of Zagreb, Faculty of Transport and Traffic Sciences, Vukelićeva 4, 10000 Zagreb, \\ Croatia; Email: borna.abramovic@fpz.hr
}

\section{*Corresponding Author: Milan Dedík}

Abstract: The development of the transport sector is a long-term and continual process. This leads to a gradual increase in economic performance, economic growth and a deeper integration of the EU countries into the global economic structures. This contribution is focused on the problem of usage of the east - west corridors for the freight transport in transit. There are proposed for the new transport connections between China and Europe. The aim of the new connections is speed up of transport process of good flows. When proposing new corridor routes and new options for interconnection of the European rail network, basic deterministic methods of network analysis - the critical path method of the CPM and the CCM critical chain can be used. The aim is also to offer new options for development of rail transportation.

Keywords: Silk route, railway, intermodal transport

\section{Introduction}

Railway transport, in contrast with the road transport, is exactly organized. The rail operator does not offer freight routes that could not be realized. As a result of the positive development of passenger transport, the freight trains are pushed into unattractive time windows in timetable that decreases their transportation quality (frequent stopping, long delivering times due transport reasons). This is a potential demand for freight transport discouraged, without being visible in the form of traffic jams as it is on the road. In order to limit this effect, it is necessary to maintain a slight prevalence of infrastructure capacity above current demand and keep acceptable quality of the routes offered for freight trains [1]. 


\section{The Rail Freight Corridors (RFC)}

The RFC represent the railway part of the TEN-T network. The Trans-European Transport Network is a European Commission policy directed towards the implementation and development of a Europe-wide network. The objective of TEN-T is to close gaps, remove bottlenecks and eliminate technical barriers that exist between the transport networks of EU Member States, strengthening the social, economic and territorial cohesion of the Union and contributing to the creation of a single European transport area. The Regulation (EU) No. 913/2010 concerning a European rail network for competitive freight requires Member States to establish international market-oriented RFCs to meet three main challenges:

- strengthening co-operation between IMs on key aspects such as the allocation of paths, deployment of interoperable systems and infrastructure development,

- finding the right balance between freight and passenger traffic along the RFCs, giving adequate capacity for freight in line with market needs and ensuring that common punctuality targets for freight trains are met,

- promoting intermodality between rail and other transport modes by integrating terminals into the corridor management process.

All the RFC are numbered and named and their names reflect both their historical origins and geographical route, such as Baltic-Adriatic or North Sea-Baltic. The indicative names will also promote a better identification and distinguish them from the other corridors, and will help to facilitate the communication with the public that are not necessarily familiar with the corridors. The projects for each of these corridors were initially created individually, but to minimize effort it was decided to incorporate them under the TEN-T concept [2].

As a result, RFCs represent the railway corridors merged with the railway corridors established under the TEN-T policy, although both the RFCs and TEN-T network are still governed by their own separate EU regulations. In 2013 the TEN-T revision policy was adopted by two regulations, namely Regulation (EU) 1315/2013 of the European Parliament and the Council on Union guidelines for the development of the trans-European transport network and Regulation (EU) 1316/2013 of the European Parliament and the Council establishing the Connecting Europe Facility. The revised TEN-T policy also defines further conditions which have to be met by the rail infrastructure, covering not only the RFCs that have been incorporated into TEN-T, but also various technical projects, such as the installation of way-side ERTMS. In the picture below this paragraph, there are shown RFC connections between Europe and Asia which are potential tool to increase the transport volume in east - west direction [3-5]. 
The aim of TEN-T and RFC is to promote international trade in the context of the Silk Road, to reduce delivery time and, in the end, to reduce the negative impact on the environment by using a greener mode of transport.

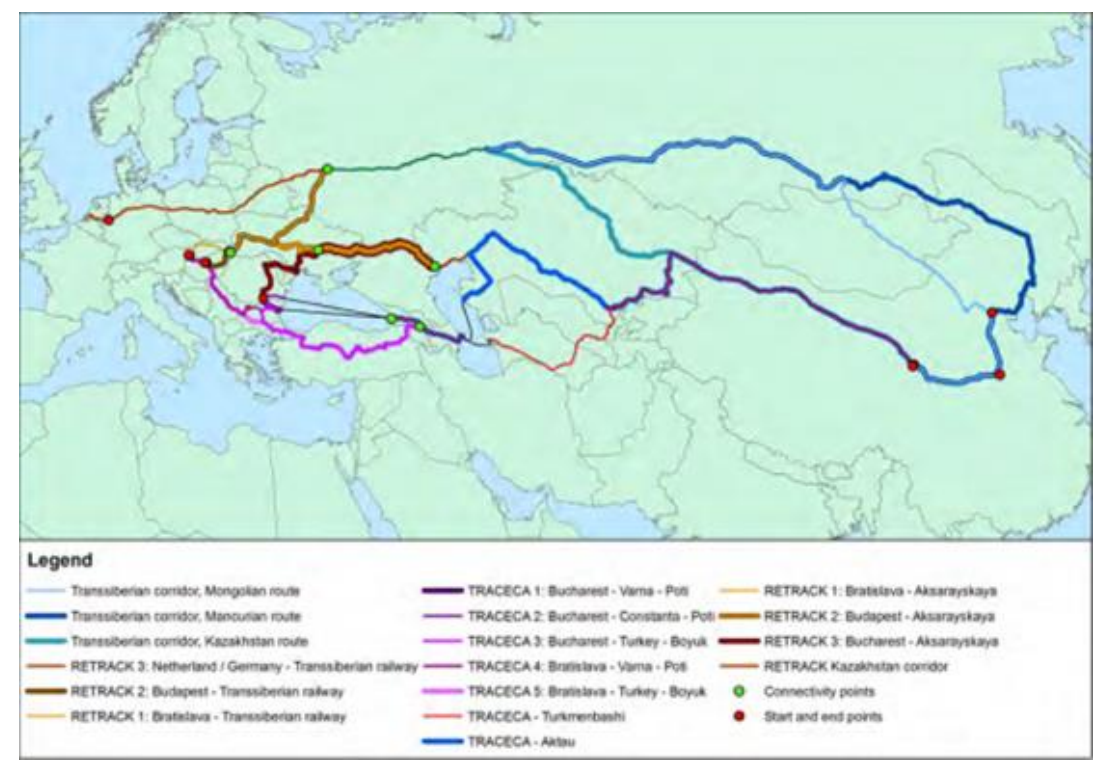

Fig. 1 Connections of Europe and China through the railway lines. Source: [3]

The current RFC regulation has successfully achieved its formal purpose in laying down rules for the establishment and organization of international rail corridors for competitive rail freight", which has had many positive effects [3]:

- improved investment planning and cooperation in several corridors

- constructive initial efforts for operational improvements

- harmonization across corridors has started

- new understandings about cross border freight operations

- new personal relationships are being developed among people who have never met physically before.

\subsection{Analysis of the Existing State of Transport Chains on Relations between China and}

\section{Europe}

According to Klapita [6], the majority of Chinese goods flow into the markets of the European Union is transported mainly by sea, which is from the southern ports of China around Singapore, Malacca and Suez Canal through the Mediterranean Sea to large European ports (see Fig.2). However, this sea route is already overloaded and, moreover, several key ones (especially in the Far East) on this route is under US control, China does not agree, because in case of deterioration of US-Chinese relations it may be relatively easily blocked. 
Part of the transit traffic flows from China to Europe via the Trans-Siberian highway (Hereinafter TSM), but it is only a relatively small proportion of transport flows. This alternative shipping with the exclusion of shipping is in many cases more advantageous than that both in terms of price and in terms of shorter transport time. Greater use of this transport route prevents the transmission infrastructure from being transmitted through this route. China in the face of export expansion, it is forced to look for other alternative routes to Europe. A third alternative that could help to relieve transport partially. The chains running through the ports are the transit railway route from China through Kazakhstan to Europe [6,7].

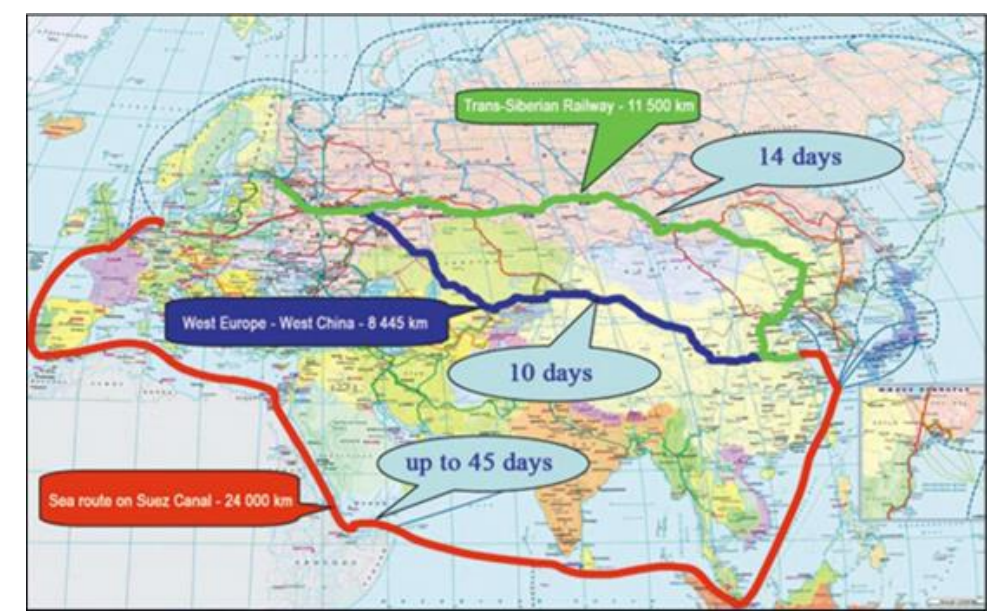

Fig. 2 Main transport corridors China - Europe. Source: [5]

According to Klapita [6], organization of transport chains is usually the responsibility of transport operators, they decide on the route and used modes of transport, respectively. Appropriate combination about their heavy-haul transport between China and Europe is (and will continue to be) water (maritime) transport, which, given the means of transport used, seagoing vessels, has a large capacity. The capacity of large seagoing container ships is several thousand TEU2 (often 8 to 16 thousand TEU). Existing shipping routes are mainly made from South China ports to major European ports, where they are then further on by rail or bus by road to Central Europe. Alternative rail transport corridors and, of course, trains have a much smaller capacity, representing only a tiny fraction percent. Therefore, these railway corridors should be considered as an addition, not for replacing existing shipping routes. Project "Silk Road", which represents a major renovation and modernization in particular rail transport infrastructure, which should link China and Europe increasing the capacity of this transport infrastructure and thereby lightening sea lanes. The problem of project implementation is not money but possible regional conflicts between transit countries.

As Europe, Russia, China and India are the main economic powers responsible for major goods exchanges within the Eurasian Continent; their desire is to have the most direct trade routes with one another. Consequently, almost all goods between the EU and the Asian Pacific region are 
shipped by sea. Land corridors through Central Asia are rarely used. In order to change this picture and reanimate the land corridors, several initiatives and projects have been undertaken in the last years $[6,8]$.

\subsection{Analysis of Transport Infrastructure in the East-West Direction}

The Slovak Republic is referred to as the transit country because of its location. The use of this potential is conditioned by a high-quality and developed transport infrastructure. In transit through the territory of the Slovak Republic, many communications of European significance are known as European transport corridors (see Fig. 3).

Two of the three Slovak RFC corridors are traced over the Bratislava hub. The BratislavaPálenisko port is the main access point of Slovakia to the European network of inland waterways, and in Dunajská Streda there is a terminal of intermodal transport. This terminal has been the largest volume of processed intermodal transport units from all Slovak intermodal transport terminals despite the fact that it is not part of TEN-T or RFC (the corridors are connected by a low-capacity and non-electrified one-track line Bratislava-Komárno). It should be remembered that there is a great potential for increasing the number of passenger trains at Bratislava and the entire Bratislava region and that many lines in important transport routes (in particular cross-border and BratislavaDunajská Streda-Komárno-HU border) are only one-track [9].

Nevertheless, the problem of insufficient capacity may remain hidden. Rail transport, unlike on the road, is tightly organized and the railroad operator does not offer freight routes that could not be realized. As a result of the (positive) development of passenger transport, trains for freight trains are pushed into unattractive locations and deterioration in their quality (frequent stopping, long stays for transport reasons). This is a potential demand for freight transport discouraged, without being visible in the form of standing columns as it is on the road. In order to limit this phenomenon, it is necessary to maintain a slight prevalence of infrastructure capacity (offers) above current demand and to adhere to acceptable trains for the acceptable quality of the routes offered. From the point of view of the limitation of interoperability, the lack of electrification of the lines (Devínska Nová Ves AT border), lack of ETCS and GSM-R equipment (Kúty - Bratislava - Nové Zámky - Komárno / Štúrovo), locally restricted space throughput, inadequate useful length of the station track and frequency of speed overrun [10].

The corridors for the international rail transport of goods in the east-west direction is the multimodal corridor number V. but also there are others lines connected Europe and Asia. Equally important is to analyze the infrastructure that is used to transport goods from Asia. Currently, the transport of goods from this area is used as an alternative to air and sea transport, rail transport. The 
reason is, in particular, that air travel is fast but costly and that shipping is economically advantageous, but the transport time is too long. In the international transport of goods, 2 routes are used primarily, as shown graphically in the picture below.

The North Corridor (red) runs from China via Russia, Belarus and Poland, and the Southern Corridor (Blue) leads via Kazakhstan, Russia, Belarus and Ukraine to Slovakia. Goods transported in containers are usually transported in Poland to Malaszewiczia and Slovakia in terminal Dobra transfers on road semi-trailers from where they are transported to their destination. There are currently several routes between Asia and Europe on these routes. All these shipments must be subjected to a transshipment or change of gradient, thereby increasing the shipping time $[9,10]$.

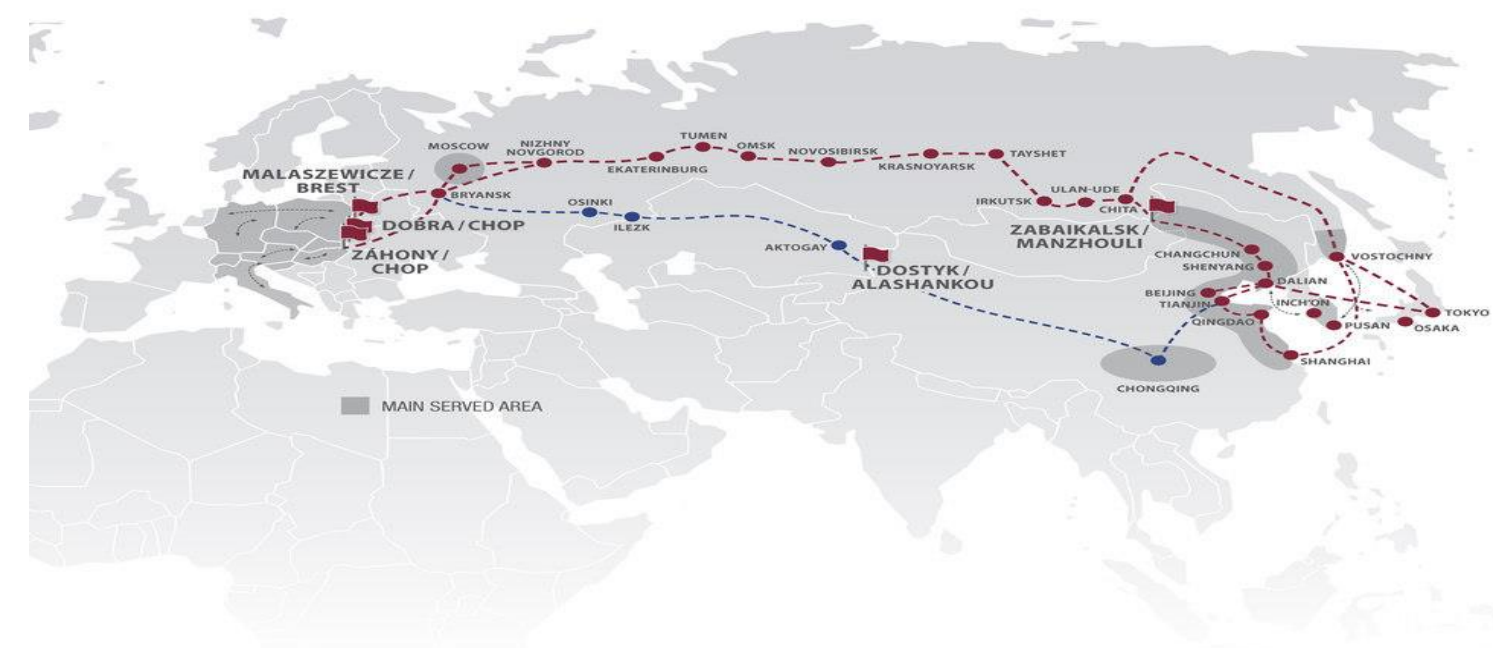

Fig. 3. The north and south railway corridor between Europe and Asia. Source: [1]

\section{Possibility of New Transport Connections in the International Rail Freight Corridors in the East - West Direction}

At present, China is making great efforts to build a silk path that should lead from China through Asia to Western Europe. This route should consolidate China's position in the world economy and speed up transport and trade between Asia and Europe. The route of the Silk route is designed in the maritime and land transport mode. The terrain of this route connects China with the countries of Central and South Asia and leads to Western Europe. This route will provide new opportunities for freight transport and international trade [8].

But it is important to build new corridors. When proposing new corridors, it is essential to analyze and optimize the existing rail network. For this propose, methods of network analysis were used. The basic deterministic methods of network analysis include, in particular, the critical path method of the CPM and the CCM critical chain, which have a significant presence in transport planning. When looking for new corridor routes and new options for interconnection of the 
European rail network, the transport role, the role of a commercial passenger, Primary route creation methods.

Using these methods, as well as various empirical and heuristic methods of decision-making (brainstorming, decision analysis methods, the method of decision tree, etc.) and also on the basis of expert consultation with a broad professional public, new corridors have been designed [11].

\subsection{Strategy of Building a Broad Gauge Line to Central and Western Europe}

The construction of a broad-gauge line to Central and Western Europe has many advantages. The main advantage is the speed, because the transport of goods will accelerate significantly compared to water transport. There are other economic and ecological advantages too. However, there are many disadvantages too. It can be political reason, because opponents argue for unwanted expansion of Russia to the west. Next reasons are commercial and economic, because there is a threat to reduce staff in transshipment station.

The issue of building a broad-gauge line to Central Europe has been up to date several years ago. In 2008, on the initiative of the Russian Railways Company, the States of Russia, Ukraine, Slovakia and Austria created a company for the construction of a broad-gauge line from the second largest city of Slovakia - Košice to the capital of Austria, to Vienna, to an international logistics terminal. Project documentation was gradually prepared. The track was to lead south of Slovakia from Košice through Lenártovce, Lučenec, Šahy, Nové Zámky, Bratislava to Vienna. Finally, after evaluating the benefits and risks, this project was cancelled and the preparatory work was stopped. However, in the second half of 2018, on the basis of new impulses and the results of several analyzes, the idea of building a broad-gauge line was again up to date. However, no specific information on the future of this line is available yet [12].

However, as part of the effective interconnection of the Eurasian continent, it would be advantageous to build the line or propose an extension of its original route. The proposal contained in chapter 3.2. is considering the construction of two new broad gauge lines in Central Europe with a continuation to Western Europe. Their building would then ensure the connection of the major European ports to the broad gauge track. These are the following 2 routes, shown in Fig. 4, while the original broad gauge track is shown in red line and the proposed broad gauge track is blue. It is an extension of the original broad-gauge line from Eastern Europe to Haniska near Kosice in Slovakia. The proposal consists in extending this wide gauge track to Vienna via the original proposed route through Southern Slovakia. In Vienna, however, the track would not be finished, but continued through Graz to the Slovenian cities of Maribor, Ljubljana and finally to the international port of Koper. The second branch of this new corridor would be a continuation of the broad-gauge 
line from the Ukrainian border crossing station Čop through the Hungarian capital Budapest with a continuation to Slovenia, where it would join in the first part of the corridor in Maribor.

It is also an extension of the original broad-gauge line that runs from Eastern Europe and finishes on the Belarus-Polish border in Brest. However, the proposal reflects extending the afore mentioned rail line through the capital of Poland-Warsaw, Poznan, then through the German capital Berlin, the major ports of Hamburg and Bremen, the capital of Amsterdam and finally to the international port of Rotterdam, where the broad gauge line will be finished.

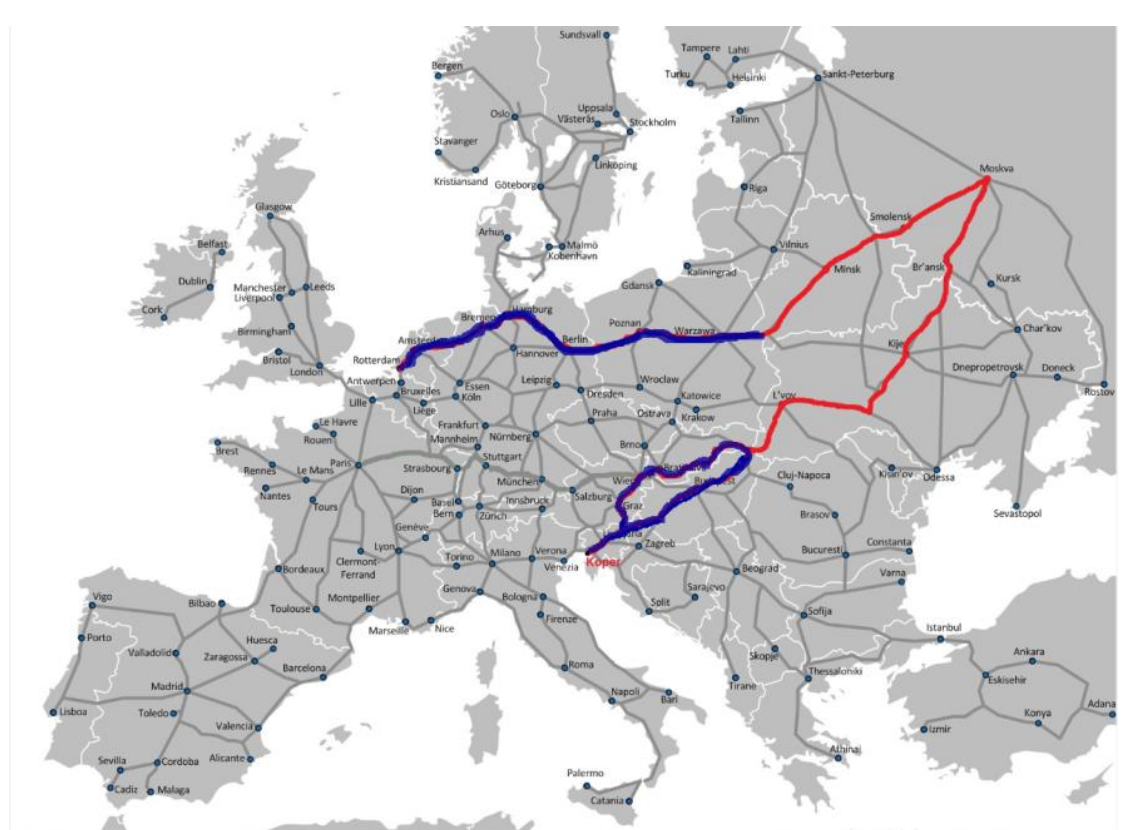

Fig. 4 Proposed extension of existing broad gauge tracks Source: Authors

The proposals for building, extending broad-gauge lines should greatly help accelerate freight rail transport from Asia and Eastern Europe to Central and Western Europe, as it would not be necessary to transship goods on normal gauge wagons. The great benefit of the proposal should also be that the broad-gauge line will be directed to Europe's largest ports (Koper, Hamburg, Rotterdam), there by achieving a more efficient interconnection of these ports with terminals and ports in Eastern Europe and Asia [13].

\subsection{The Use of the Northern Sea Route Connecting Europe and Far East}

The connection between Europe and Southeast and East Asia is currently being exploited by a southern sea route, mainly from the port of Rotterdam, through the Gibraltar canal, the Suez Canal and the Indian Ocean to major ports such as the Port Shanghai, Hong Kong, Singapore, Osaka, Nagoya, Yokohama etc. But geographically more advantageous and faster would also be the North Sea Route that would lead across the North Ice Ocean along the north coast of Russia through the Bering Canal to the Pacific Ocean and then to the afore mentioned major ports. However, this route 
is limited by climatic conditions, which are not optimal especially in winter months. However, at present, with the increasing global warming trend, it is evident that the use of this Northern Sea Route will certainly be up to date and possibly the whole year in the future.

At the same time using this route and building a broad-gauge line to the international port of Rotterdam or. Hamburg would have received these two variants of direct and relatively fast connection with international Asian ports. The North Sea Route is shown in Fig. 5 by red color, the current broad gauge line is shown in blue and the broad gauge line proposed in purple [6].

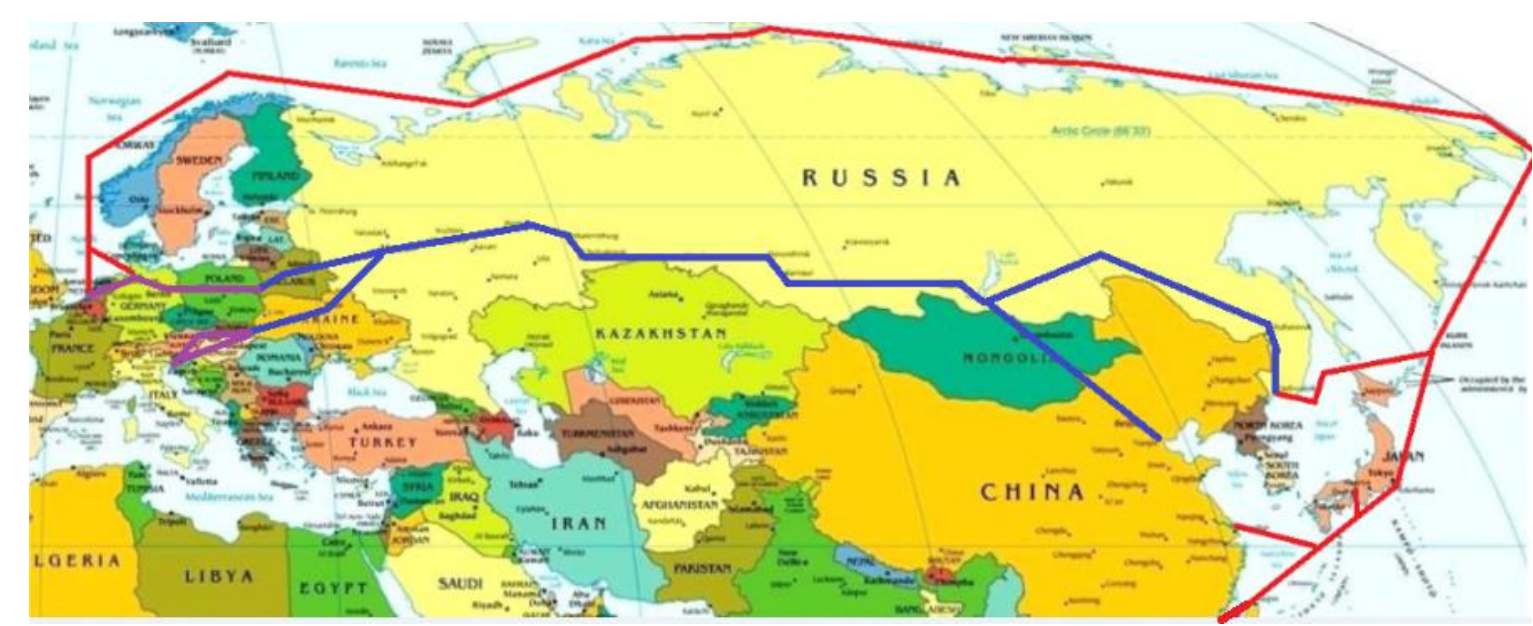

Fig. 5 Connection of European and Asian ports with the Northern Sea Route and Rail. Source: authors

\section{Conclusion}

When transporting large number of goods from China to Europe, the sea transport is most essential. Alternative routes that are created by inland routes, especially by rail, are very preferred in many cases. However, it is important to look for solutions that will be effective to transport the goods fast and cheap. The project of Silk Road represents a major renovation and modernization of the railway infrastructure. It should link China and Europe. It aims to increase the capacity of the transport infrastructure and also to alleviate the transport of goods by sea.

Considering the prognosticated increase of transport outputs from China into European Union countries it is necessary to look for such solutions that will reduce transportation chains of water transport and will move the part of transport outputs to the railway transport. The contribution explained the effective use of the potential of building a broad gauge line to Central and Western Europe. Using the methods mentioned in $3^{\text {rd }}$ chapter new corridors have been designed. However, in order to assess the effectiveness of their construction, it will be necessary to carry out the economic and financial analysis for further scientific research. Also, there should be made the modeling and simulation of traffic service on the proposed railway lines, their capacity, train traffic diagram and so on in the future. 


\section{References}

[1] Vudmaska, M. (2017). Draft measures to increase rail freight performance in the east - west direction. Diploma thesis, University of Žilina, Slovakia.

[2] Ministry of Transport and Construction of the Slovak Republic. (2016). Strategic Transport Development Plan of Slovakia by 2030. Strategic document.

[3] European Rail Freight Association. (2010). Further strengthening of Rail Freight Corridors. Strategic document.

[4] European court auditors. (2016). Railway freight transport in the EU: still not on the right track. Luxembourg, ISBN 978-92-872-4601-1, ISSN 1977-5776, DOI: 10.2865/638450.

[5] Daniš, J., Černá, L. \& Bartuška, L. (2016). Costs comparison and the possibilities of increasing the transport capacity with a selection of the appropriate railway wagons. Our Sea 63(3), 93-97.

[6] Klapita, V. (2017). Analysis of transportation from China to the European Union. Logistics monitor 6, 77-82.

[7] Záhumenská, Z. \& Gašparík, J. (2017). Supporting the connection the logistics centers to rail network. Procedia Engineering 192, 976-981.

[8] Kudláč, S., Majerčák, J. \& Majerčák, P. (2017). Comparison of different variants of logistics chain with the use of air transport using the software application. Transportation Research Procedia 28, 45-50.

[9] Dragićević B., Schöbel A. \& Milinković S. (2018). Traffic optimization in TENT's industrial railway transport by using open track and kronecker algebra. In International conference on traffic and transport engineering 4, (pp. 711 - 716) .University of Belgrade, Serbia.

[10] Černá, L., Stopka, O. \& Zitrický, V. (2016). Methodology for measuring the customer satisfaction with the logistics services. Our Sea 63(3), 189-194.

[11] Blašković, Z.J., Abramović, B. \& Šipuš, D. (2017). A Strategic Model of Sustainable in the city of Zagreb and its Surrounding Area. International Journal for Traffic and Transport Engineering (IJTTE) 7, 430-442.

[12] Drábek, M., Jánoš, V. \& Michl. Z. (2016). Quantitative Determination of Bottlenecks in Railway Networks with Periodic Service. OSTAŠEVICIUS, V., ed. In Proceedings of 20th International Conference Transport Means, (pp. 594-598). Juodkrante.

[13] Hansen, A. \& Pachl, J. (2008). Railway timetable and traffic University of Technology Delft, Technische Universität Braunschweig, Eurailpress. 